\title{
Local Brittle Zones and the Role of Niobium
}

\author{
BHADESHIA Harshad K. D. H. \\ University of Cambridge, Materials Science and Metallurgy, U. K. \\ hkdb@cam.ac.uk
}

Keywords: Niobium, microalloyed steels, martensite-austenite mixtures, local brittle zones, theory

\begin{abstract}
There is a confused and contradictory literature on the role of small concentrations of niobium on the development of the so-called local brittle zones in steels. These zones consist of a mixture of martensite and austenite and hence, their formation should be predictable using modern microstructure calculation methods. Following an assessment of the most relevant literature, a mathematical model is presented which enables three quantities to be calculated, the fraction of martensite, the carbon concentration of the martensite, and its ability to influence toughness. Examples are presented for particular linepipe steels, and then the generic effect of alloying elements other than niobium, on the development of local zones.
\end{abstract}

\section{The Local Brittle Zone as an Entity}

Local brittle zones (LBZs) are small regions of hard, brittle phase that form in the heat affected zones (HAZs) of multipass welds [1]. They usually contain untempered martensite that can lead to scatter in toughness data when the test specimen samples a brittle zone [2]. Such scatter reduces confidence in design because of the existence of a few poor values which fall out of the desired range. Experimental data have been interpreted to conclude that the lower bound toughness values deteriorate as the volume fraction of martensite in the form of LBZs increases [3]. However, the same data can be interpreted to indicate that there is a minimum in the toughness as a function of increasing fraction of martensite [4]. Local brittle zones are often treated without a consideration of their detailed microstructure but to make rational assessments it is necessary to address the following questions in a quantitative manner:

1. How hard does a LBZ have to be in order to influence scatter in toughness? Or is it the hardness relative to the surrounding material that influences its ability to act as a brittle zone?

2. How big does a LBZ have to be in order to matter, relative to the size of the plastic zone in the test used to determine toughness?

3. Does the shape of the LBZ matter?

4. How many tests are required in order to establish a probability of failure based design?

Given these unknowns, it is not surprising that the critique by Liessem and Erdelen-Peppler [5] fails to resolve the fourth query in this list, other than to suggest a change in specification that would allow repeated testing of rejected pipes until the specification is met. The practical problem is that all pipes contain LBZs when longitudinally welded, and it is luck that determines whether the small-scale tests hit an LBZ. The real issue should include a specification of an acceptable level of risk, and probabilistic testing to see whether the material and process combination manages that risk. The generation of probabilistic data is of course, expensive.

\section{Martensite/Austenite Constituent}

The martensite-austenite (MA) constituent is a rather clumsy name given to what is essentially a mixture of untempered martensite embedded in carbon-enriched retained austenite. When 


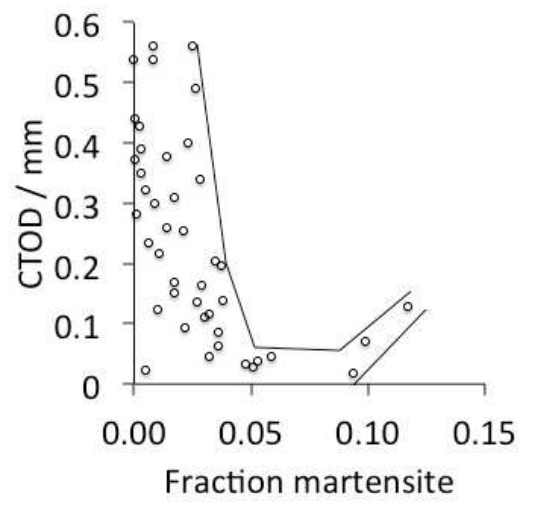

Fig. 1: Crack tip displacement values $\left(-30^{\circ} \mathrm{C}\right)$ measured on simulated heat-affected zone microstructures in a variety of steels, as a function of the martensite fraction. Note that the hardness of martensite is not constant but is expected to vary as a function of heat treatment and chemical composition. Adapted from [3]

transformations such as Widmanstätten ferrite or bainite occur at temperatures greater than that at which martensite can form $\left(M_{S}\right)$, the residual austenite becomes enriched in carbon if cementite precipitation is avoided. Its martensite-start temperature is therefore reduced to $M_{S}^{r}$. In modern low-carbon steels, the fraction of this residual austenite tends to be small, and some of it may partly decompose into martensite if $M_{S}^{r}$ is greater than ambient temperature. It is this small quantity of martensite and carbon-enriched austenite that is the MA constituent.

This simple mechanism for the genesis of the MA constituent helps establish the role of alloying elements, cooling rates and austenite grain size. The ability to calculate the volume fraction and chemical composition of MA was demonstrated some time ago in predominantly bainitic microstructures, on the basis of the detailed phase transformation theory $[6,7]$; a simple numerical example is given in [8]. It relies on the fact that the bainite reaction stops when the carbon concentration of the austenite achieves that given by the $T_{0}$ curve; similar limiting conditions can be derived if the microstructure contains other ferritic phases.

A full description of the MA constituent should include:

1. the proportions of martensite and austenite in the constituent;

2. the chemical compositions of the martensite and austenite. This is necessary in order to estimate the hardness (see for example, [7]. MA is formed from the residue of austenite that is left untransformed following the growth of phases such as ferrite, Widmanstätten ferrite and bainite. All of these leave the austenite richer in carbon provided the average concentration of carbon in the steel is greater than its solubility in ferrite. If the volume fraction of MA is large then its carbon concentration will be low; assuming that brittle behaviour is associated with high carbon, the phase may be less harmful at sufficiently large fractions.

3. The shape of the MA. When MA is confined between plates of ferrite, the retained austenite within it is more stable than when it is present as blocks between differently oriented plates $[6,7]$. Films of retained austenite are not considered to be damaging to toughness.

4. The mechanical properties of the MA region relative to its surroundings.

Some of these items can be estimated as described in the next section $[4,6,7,9,10]$. The procedure is straightforward (Fig. ??a, beginning with the calculation of the martensite-start temperature $M_{S}$ of the steel $[11,12]$. It is then assumed that the bainite transformation is allowed to proceed to its maximum extent in the absence of cementite precipitation at all temperatures down to $M_{S}$. This means that the carbon concentration $x_{\gamma}$ of the austenite at the completion of the bainite reaction is given by the $T_{0}$ curve for the steel, which represents the locus of all points on a plot of temperature versus carbon content where austenite $(\gamma)$ and ferrite $(\alpha)$ of the same composition have identical free energies. Thus, $x_{\gamma}=x_{T_{0}}\left\{M_{S}\right\}$, and this can be used to calculate the fraction of bainite $V_{\alpha_{b}}$. 
This carbon enriched austenite is then allowed to cool to ambient temperature, and some of it will transform into martensite as calculated using the Koistinen and Marburger equation [13]. These calculations are now illustrated in the context of X80 pipeline steels. This procedure is justified on the basis of the mechanism of the bainite reaction summarised in [14,Chapter 6$]$ and an example calculation designed for teaching purposes can be downloaded [15].

\section{Calculations for $\mathrm{X} 80$ steel}

The examples given here illustrate the calculation of the volume fractions and chemical compositions of each of the phases present in the the MA constituent in $\mathrm{X} 80$, given that the entire microstructure contains only bainite, martensite and retained austenite. This simplifies the calculations because the bainite reaction is limited by the $T_{0}$ curve, and consistent with that, the carbon concentration of MA is found to be independent of the average value in the steel [16]. The considered are listed in Table 1, of which only one is a commercial alloy and the other two are hypothetical modifications to illustrate the roles of carbon and manganese. ${ }^{1}$

Table 1: Chemical compositions of steels studied, wt\%, and calculated martensite-start temperature $[11,12]$ of fully austenitic steel.

\begin{tabular}{lccccccc}
\hline Alloy & $\mathrm{C}$ & $\mathrm{Si}$ & $\mathrm{Mn}$ & $\mathrm{Ni}+\mathrm{Mo}$ & $\mathrm{Nb}+\mathrm{Ti}$ & $\mathrm{Al}$ & $M_{S} /{ }^{\circ} \mathrm{C}$ \\
\hline X80 [17] & 0.073 & 0.23 & 1.76 & 0.56 & 0.05 & 0.033 & 444 \\
X80, reduced carbon & $\mathbf{0 . 0 5 0}$ & 0.23 & 1.76 & 0.56 & 0.05 & 0.033 & 452 \\
X80, increased manganese & 0.073 & 0.23 & $\mathbf{2 . 2 0}$ & 0.56 & 0.05 & 0.033 & 425 \\
\hline
\end{tabular}

When thermomechanically processed, $\mathrm{X} 80$ steels contain bainite as the majority phase $\left(\alpha_{b}\right)$ with much smaller quantities of martensite and retained austenite. Because of the low carbon concentration and the presence of niobium, cementite precipitation may not accompany for the formation of bainite [10], thus permitting the austenite to retain any carbon partitioned from the bainite.

(a)



Fig. 2: (a) Flow chart illustrating the calculation. (b) Calculated $T_{0}$ curve for X80 steel. $\bar{x}$ represents the average carbon concentration of the steel, for example, $0.073 \mathrm{wt} \%$ (Table 1.

The calculated martensite-start temperature of the fully austenitic $\mathrm{X} 80$ steel is $444^{\circ} \mathrm{C}[11,12]$. The calculated $T_{0}$ curve is given in Fig. 2 . If it is assumed that the maximum fraction of bainite is

\footnotetext{
${ }^{1}$ We assume that cementite precipitation does not occur, which is realistic at the sort of cooling rates encountered after thermomechanical processing. However, in some X80 variants, allotriomorphic ferrite $(\alpha)$ can be present in which case the carbon partitioned from the ferrite into the austenite prior to the onset of bainite must be taken into account using a mass balance equation by replacing the volume fraction $V_{\alpha_{b}}$ by $V_{\alpha}+V_{\alpha_{b}}$ in equation 1.
} 
achieved at a temperature just above $444^{\circ} \mathrm{C}$, then the transformation must stop when the carbon concentration of the residual austenite, i.e. $x_{\gamma}$ reaches the $T_{0}$ curve, i.e., $x_{\gamma}=0.66 \mathrm{wt} \%$. From mass balance,

$$
V_{\alpha_{b}} x_{\alpha_{b}}+V_{\gamma} x_{\gamma}=\bar{x}
$$

where $V_{\alpha_{b}}$ is the volume fraction of bainitic ferrite, $V_{\gamma}$ is that of the residual austenite at the transformation temperature with $V_{\gamma}=1-V_{\alpha_{b}}$ and $\bar{x}$ is the average carbon concentration in the alloy. Taking $x_{\alpha_{b}}$ to be $0.02 \mathrm{wt} \%$ (rough solubility of carbon in ferrite) and setting $x_{\gamma}=x_{T_{0}}$ at $440^{\circ} \mathrm{C}$, gives from the lever rule applied to the $T_{0}$ curve,

$$
V_{\alpha_{b}}=\frac{x_{T_{0}}-\bar{x}}{x_{T_{0}}-x_{\alpha_{b}}} \equiv \frac{0.66-0.073}{0.66-0.02}=0.92 \quad \text { and } \quad V_{\gamma}=0.08
$$

Given that $x_{\gamma}=0.66 \mathrm{wt} \%$, its $M_{S}^{r}$ becomes $166^{\circ} \mathrm{C}$, so that using the Koistinen and Marburger equation, the fraction of austenite retained $\left(\gamma_{r}\right)$ in the final microstructure obtained by cooling to ambient temperature, is given by

$$
\begin{aligned}
V_{\gamma_{r}} & =V_{\gamma} \times \exp \left\{-0.011\left(M_{S}^{r}-25\right)\right\} \\
& =0.08 \times \exp \{-0.011(166-25)\}=0.02
\end{aligned}
$$

It follows that the amount of martensite $V_{\alpha^{\prime}}=0.08-0.02=0.06$. The final microstructures are listed in Table. The hardness of the martensite is expected to be in the region of $700 \mathrm{HV}$ [8]. One

Table 2: Summary of the calculated microstructures

\begin{tabular}{lcc|cc|cc}
\hline \multirow{2}{*}{ Phase } & \multicolumn{2}{c}{ X80 pipe steel } & \multicolumn{2}{c}{ Reduced-carbon X80 } & \multicolumn{2}{c}{ Increased Mn X80 } \\
& Volume \% & Carbon / wt\% & Volume \% & Carbon / wt\% & Volume \% & Carbon / wt\% \\
\hline Bainitic ferrite $\alpha_{b}$ & 92 & $\approx 0.02$ & 95 & $\approx 0.02$ & 0.98 & $\approx 0.02$ \\
Martensite $\alpha^{\prime}$ & 6 & 0.66 & 4 & 0.66 & 6 & 0.65 \\
Retained austenite $\gamma_{r}$ & 2 & 0.66 & 1 & 0.66 & 2 & 0.65 \\
\hline
\end{tabular}

approximation made here is that the formation of bainite stops at the $M_{S}$ temperature of the steel as a whole, i.e., $444^{\circ} \mathrm{C}$; permitting it to proceed to an even lower temperature would reduce the $\alpha^{\prime}+\gamma_{r}$ fraction, and increase the amount of retained austenite st the expense of martensite. The calculations are in a thermodynamic framework, and kinetic effects could increase the amount of martensite, at the expense of bainite. However, a larger fraction of martensite would necessarily have a lower carbon concentration and hence would be softer.

\section{Other Considerations}

The purpose here is to critically assess published inferences about the connexion between niobium and MA constituents.

That niobium in solid solution increases hardenability is well known. In a study limited to the metallography of high-carbon steel $(0.15 \mathrm{C}, 0-0.03 \mathrm{Nb} w \mathrm{wt} \%)$ Furuhara et al. [10] concluded that niobium dissolved in austenite retards its decomposition of residual austenite into a mixture of ferrite and cementite. Although mechanical properties were not studied, the lack of cementite is likely to benefit toughness $[6,7]$.

Matsuda et al. [16] undertook a major review, motivated by the claim that MA constituents are detrimental to the toughness of welded joints, where repeated heating and cooling cycles create regions in the HAZ that are heated into the two phase $\gamma+\alpha$ field. The austenite created by this 
intercritical treatment is richer in carbon than the average concentration in the steel, subsequent cooling can therefore produce hard regions upon martensitic transformation. It is stated specifically that carbide-forming elements such as $\mathrm{Mo}, \mathrm{Nb}$ and $\mathrm{V}$ promote MA because the retard the diffusion of carbon during the transformation from austenite to ferrite and hence the thermal decomposition of the MA constituent. The calculations in Table 3, done using DICTRA [18] and associated mobility databases, show clearly that none of the carbide-forming elements, including niobium, actually decrease the diffusion coefficient of carbon in austenite. In fact, the influence of substitutional solutes on the diffusivity of carbon in austenite is insignificantly small.

Chemical segregation during solidification can enhance the formation of MA constituents, as is known in the context of line pipe steels where carbon-rich bands arise due to the non-uniform distribution of manganese [19]. There is no evidence as yet that the segregation of niobium gives rise to bands. Indeed, results are presented (Fig. 23, [16]) to show that the coarse-grained heat-affected zone in $9 \%$ nickel steel exhibits identical toughness for niobium-containing and niobium-free alloys.

Table 3: Influence of niobium on the diffusivity of carbon in austenite at $1000^{\circ} \mathrm{C}$.

\begin{tabular}{lc}
\hline Composition / wt\% & Diffusivity $\mathrm{m}^{2} \mathrm{~s}^{-1}$ \\
\hline Fe- $0.1 \mathrm{C}$ & $2.25011 \times 10^{-11}$ \\
Fe- $0.1 \mathrm{C}-0.5 \mathrm{Nb}$ & $2.25094 \times 10^{-11}$ \\
Fe- $0.1 \mathrm{C}-0.5 \mathrm{Mo}$ & $2.25016 \times 10^{-11}$ \\
Fe-0.1C-0.5Mn & $2.24938 \times 10^{-11}$ \\
\hline
\end{tabular}

In contrast to the work described above, Ishikawa et al. [20] present data showing how the fracture-assessed transition temperature increases with niobium additions, claiming that the deterioration in toughness is a consequence of the greater quantity of MA associated with niobium. Remarkably however, they do not present any evidence that niobium increases the fraction of MA; the paper does not include any microstructural characterisation as a function of the niobium concentration.

Hatano et al. [21] studied three similar steels but with one containing $0.04 \mathrm{wt} \% \mathrm{Nb}$ and another with an enhanced manganese concentration. The worst toughness was recorded in the niobium containing steel. However, the entire analysis is based on experimental melts which have not been thermomechanically processed, whereas the prime reason for adding microalloying elements it to exploit such processing. They also fail to report strength or hardness data, which makes it difficult to interpret the toughness. Comparisons of toughness should be made at constant strength. The microstructural studies reported are at a low resolution and the size of the MA constituents is reported without uncertainties, making it impossible to assess whether any differences are statistically significant. The conclusion reached that strong carbide-forming elements are to be avoided in the context of MA is not justified by the data reported, and the $T_{0}$ concept described here emphasises the role on hardenability rather than on carbide-forming tendencies.

\section{Conclusions}

1. There is persuasive evidence that the presence of the MA constituent in the heat-affected zones of welds can lead to the deterioration of toughness. However, the wide use of the term MA constituent hides many complexities about shape, size and composition. It is unwise to claim that such regions are always detrimental. There are many steels in service where such 
mixtures of austenite and martensite are considered beneficial to the properties, as reviewed elsewhere [22-25].

2. General statements indicating a detrimental effect of niobium through its influence on the microscopic regions containing martensite and austenite mixtures are not supported by evidence in the literature reviewed. The analysis using the $T_{0}$ concept shows that there are many solutes that influence the development of such microstructures, and that their roles can easily be quantified by calculation.

References

[1] D. P. Fairchild: Local brittle zones in structural welds: in: J. Y. Koo (Ed.), Welding Metallurgy of Structural Steels: TMS-AIME, Warrendale, Pennsylvania, USA, 1987: pp. 303-318.

[2] K.-H. Schwalbe, M.Koçak: Fracture mechanics of weldments, problems and progress for weldments: in: S. A. David, J. Vitek (Eds.), International Trends in Welding Science and Technology: ASM International, Ohio, USA, 1992: pp. 479-494.

[3] S. Aihara, K. Okamoto: Influence of LBZon HAZ toughness of TMCP steel: in: D. G. H. J. T. Hickey, M. D. Randall (Eds.), Metallurgy, Welding and Qualification of Microalloyed Steel Weldments: American Welding Society, Florida, USA, 1990: pp. 402-427.

[4] S. Suzuki, G. Rees, H. K. D. H. Bhadeshia: Modelling of brittle zones in the HAZ of steel welds: in: T. Zacharia (Ed.), Modelling and Control of Joining Processes,: American Welding Society, Florida, USA, 1993: pp. 186-193.

[5] A. Liessem, M. Erdelen-Peppler: A critical view on the significance of HAZ toughness testing: in: Proceedings of International Pipeline Conference: ASME, New York, USA, 2004: pp. 1-8.

[6] H. K. D. H. Bhadeshia, D. V. Edmonds: Metal Science 17 (1983) 411-419.

[7] H. K. D. H. Bhadeshia, D. V. Edmonds: Metal Science 17 (1983) 420-425.

[8] R. W. K. Honeycombe, H. K. D. H. Bhadeshia: Steels: Microstructure and Properties, 2nd edition: Butterworths-Hienemann, London, 1995.

[9] H. K. D. H. Bhadeshia, D. V. Edmonds: Acta Metallurgica 28 (1980) 1265-1273.

[10] T. Furuhara: Materials Science and Technology 26 (2010) in press.

[11] H. K. D. H. Bhadeshia: Metal Science 15 (1981) 175-177.

[12] H. K. D. H. Bhadeshia: Metal Science 15 (1981) 178-180.

[13] D. P. Koistinen, R. E. Marburger: Acta Metallurgica 7 (1959) 59-60.

[14] H. K. D. H. Bhadeshia, R. W. K. Honeycombe: Steels: Microstructure and Properties, 3rd edition: ButterworthHeinemann, London, 2006.

[15] H. K. D. H. Bhadeshia: Calculation of structure (2013). URL http://www.msm.cam.ac.uk/phase-trans/2000/C9/AEX2.pdf

[16] F. Matsuda, Y. Fukada, H. Okada, C. Shiga, K. Ikeuchi, Y. Horii, T. Shiwaku, S. Suzuki: Welding in the World 37 (1996) 134-154.

[17] S. Y. Shin, B. Hwang, S. Lee, N. J. Kim, S. S. Ahn: Materials Science \& Engineering A 458 (2007) 281-289.

[18] J. O. Andersson, T. Helande, L. Hoglund, P. Shi, B. Sundman: CALPHAD 26 (2002) 273-312.

[19] H. K. D. H. Bhadeshia: Bainite in Steels, 2nd edition: Institute of Materials, London, U.K., 2001.

[20] N. Ishikawa, T. Shinmiya, S. Igi, J. Kondo: Toughness evaluation on seam weld HAZ of high strength UOE linepipe: in: 6th International Pipeline Conference: ASME, New York, USA, 2006: pp. IPC2006-10245.

[21] H. Hatano: Unknown? (2005) ?

[22] B. DeCooman: Current Opinion in Solid State and Materials Science 8 (2004) 285-303.

[23] P. J. Jacques: Current Opinion in Solid State and Materials Science 8 (2004) 259-265.

[24] H. K. D. H. Bhadeshia, M. Lord, L.-E. Svensson: Transactions of JWRI 32 (2003) 91-96.

[25] H. K. D. H. Bhadeshia: Proceedings of the Royal Society of London A 466 (2010) 3-18. 